\title{
Experimental investigation of the heat exchange intensity
}

\author{
Vladimir Davletbaev ${ }^{1}$, Natalia Rydalina $^{2, *}$, and Elena Antonova ${ }^{2}$ \\ ${ }^{1}$ Product company OOO MzkKstroy, 625001, Russia, Tyumen, 70/3 Kommunisticheskaya Str. \\ ${ }^{2}$ Industrial University of Tyumen, Institute of service and sectoral management, Department of \\ Industrial heat engineering, 625000, Russia, Tyumen, 38 Volodarskogo St.
}

\begin{abstract}
We study heat exchangers at the experimental setup aiming at the energy-saving. The feature of this heat exchange process is of the fact that the working medium is a porous metal. The pores are filled with freon and operation of the refrigeration unit condenser is studied. The scheme of the experimental setup and experiment methodology are given. The results of the experiment and its processing are also presented.
\end{abstract}

\section{Introduction}

Nowadays, the task of energy saving in various industries, equipment and public utilities is very urgent. For this purpose one use new technologies, new designs, new materials, which include porous metals [1,2]. The use of porous metals is very promising for creation of compact, highly efficient heat exchangers for various purposes, which are the key element of refrigerating units, heat pumps, steam turbine condensers $[3,4]$. Porous metals can increase the heat removal for $100-150$ times.

There is a setup for studying the efficiency of such metals in steam turbine condensers at the Industrial University of Tyumen.

The object of our research is the process of heat exchange in heat exchangers of the "water-gas" type with a phase transition of the heat-transfer agent.

Application of the heat exchange intensification using porous metals became a basis of various heat exchangers in which the channels or annular spaces are filled with various types of porous metals using their various designs [5-7].

Heat exchangers with the coolant flow with phase transition are of various designs.

The Invention Certificate No. 494585 (USSR, 1975) describes a heat exchanger with a three-layer wall adjacent to the heat transfer surface. The wall has different porosities of the outer and middle layers.

In order to increase the intensification of heat exchange and to reduce its size the Invention Certificate No. 1460575 (USSR, 1989) proposes usage of heat exchange intensifiers and liquid phase separators that are installed inside the heat exchanging tubes at the outlet of them and constitute a perforated tube. Filters which are isolated one from another are installed on the outer surface of the separators. They are made in the form of annular

\footnotetext{
* Corresponding author: rydalinanv@tyuiu.ru
} 
porous gaskets, porosity of which increases along the length of the bushing outlet in the direction of the exit of the heat exchange tubes. At the same time between the inner surface of the heat exchange tubes and filters in the places of their joining the washers of highly heatconducting porous material of the same porosity are additionally installed.

The use of heat-sensitive ribs, installed with the ability to change the angle of inclination, is presented in the Invention Certificate No. 1469288 (USSR, 1989). The surface on the side of the ribs additionally contains a sheet with capillary holes, forming a cavity with the surface filled with capillary-porous material.

Currently, the variety of porous structures and the corresponding heat exchangers complies with the specific case of their use. The majority of works are intended for coolants of the "gas-gas" and "gas-water" types with a single-phase coolant, which have found their application in rocket engines, for cooling gas turbine blades, electronic components and other heat-stressed devices [8-10].

In addition, interesting designs of heat exchangers with phase transition of the coolant are proposed in patents No. 3168137 (USA, 1965), No. 3170512 (USA, 1965), No. 3394756 (USA, 1968), No. 4458748 (USA, 1985).

Sometimes porous materials are used for temperature stabilization [12] and control of the heat removal power. In the heat exchange element, the coolants flow through porous inserts separated by a wall. Regulation of heat removal is carried out using a cavity in the separating wall connected to sources of intermediate coolants with various thermal conductivity coefficients, equipped by flow regulators (Invention Certificate No. 1423905 (USSR, 1988). In some constructions it is recommended to fill the cavity of the wall with a porous structure (Invention Certificates No. 1223009 (USSR, 1986) and No. 1223020 (USSR, 1986)).

Porous structures have found their application in heat exchange elements and heat exchangers with volumetric heat emission (Invention Certificate No. 746960 (USSR, 1989), patent No. 1241441 (United Kingdom, 1971) and No. 1446417 (United Kingdom, 1976), patent No. 3833791 (USA, 1974) and No. 3944490 (USA, 1976)).

Analysis of the literature has showed that the active work is performed aiming at creation of heat exchangers using porous materials. The novelty of the research is in the creation of a unit which allows studying heat transfer in porous structures.

The possibility of creating a heat exchanger of the "water-gas" type with a phase transition of the coolant is based on studies of I. Popov [13] and other authors [14-18], who indicate the possibility of this type of heat exchange on the example of highly porous materials.

The purpose of this work is to experimentally study the intensity of heat transfer in coolants of the "water-gas" type with a phase transition of a coolant containing porous inserts of various porosities.

In this regard, experimental studies were carried out, consisting in the measurements of indicators, which estimate the heat transfer intensity. The obtained experimental data was mathematically processed. The conclusions on the possible improvements of the created experimental unit were drawn.

\section{Model development}

The scheme of the experimental test unit is presented in Figure 1. It allows one to estimate the intensity of heat exchange in heat exchangers containing porous structures. 




Fig. 1. The principle scheme of the experimental test unit: 1 - Electric motor; 2 - Compressor; 3 Condenser; 4 - Throttle; 5 - Heat exchanger with porous inserts; 6 - Standard heat exchanger; 7 Temperature sensor; 8 - Flow meter; 9 - Pressure sensor; 10 - Expansion tank; 11 - Pump; 12 - Boiler.

Copper heat exchangers with inserts are an assembly of 19 copper tubes for the water flow, which are dressed in four aluminum cylindrical inserts of the equal porosity. In the first heat exchanger, the porosity $(\mathrm{P})$ of the inserts is 0.53 , in the second heat exchanger, the porosity of the inserts is 0.52 and in the third heat exchanger, the porosity of the inserts is 0.51 . The internal part of the heat exchanger with porous inserts is shown in Figure 2.

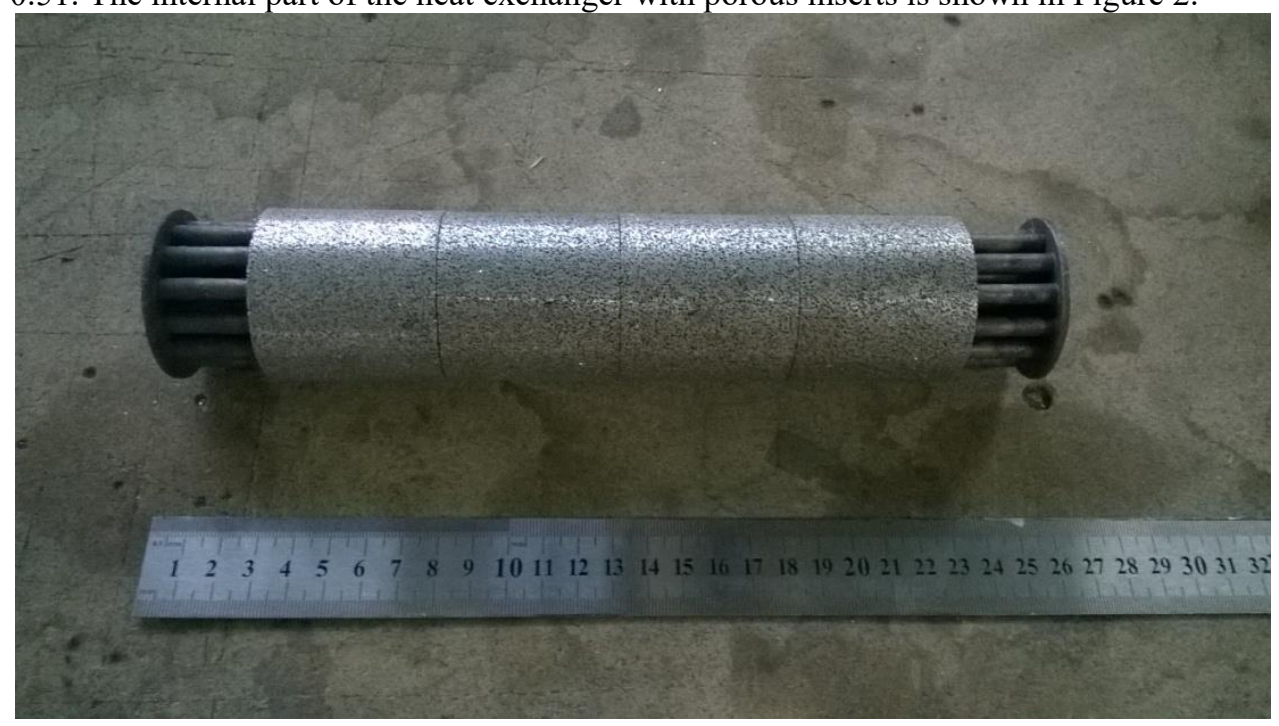

Fig. 2. Inserts made of porous aluminum

Porous inserts are cylinders made of porous aluminum with a height of $50 \mathrm{~mm}$ and a diameter of $49 \mathrm{~mm}$. Each insert has 19 holes with a diameter of $6 \mathrm{~mm}$, for tubes along which water moves. 
The experiment was carried out as follows. With the help of a ball valve, heat exchangers not participating in the experiment were blocked. Freon circuit is also equipped with ball valves, allowing blocking the freon flow into heat exchangers not participating in the experiment.

When varying the water flow using a ball valve, we measured the temperature change at the inlet and outlet of the heat exchanger. The flow rate was also recorded. In order to exclude random errors, we took 10 readings of the temperature change with each change in consumption.

The experiments were carried out for each heat exchanger at four values of water flow. As a result, an array of data was obtained that allows us to estimate the intensity of heat transfer by an indirect method.

\section{Results and discussion}

The obtained data was processed, and the coefficient of the data set variation was estimated basing on the temperature difference at the inlet and outlet of the heat exchanger. The data set variation coefficients were determined for each change in mass flow rate and ranged from 1 to $8 \%$. This states for small deviations from the average indicators per totality and homogeneity of the totality of the obtained data.

The intensity of heat transfer was determined on the basis of the heat balance equation and the power of the heat exchanger (1):

$$
Q=M_{1} \cdot c_{p m_{1}} \cdot\left(t_{1}-t_{2}\right)=M_{2} c_{p m_{2}}\left(\tau_{1}-\tau_{2}\right)=k H \theta_{m},
$$

where M1 is mass flow rate of water, $\mathrm{kg} / \mathrm{s} ; \mathrm{M} 2$ is mass flow rate of freon, $\mathrm{kg} / \mathrm{s} ; \mathrm{c}_{\mathrm{pm}_{1}}$ and $\mathrm{c}_{\mathrm{pm}_{2}}$ are isobaric mass specific heat capacities for water and freon; $t_{1}$ and $t_{2}$ are water temperature before and after the evaporator; $\tau_{1}$ and $\tau_{2}$ are freon temperatures before and after the evaporator; $k$ is the heat transfer coefficient $\mathrm{W} /\left(\mathrm{m}^{2} \cdot \mathrm{K}\right) ; H$ is the area of heat transfer surface; $\theta_{m}$ is the average temperature coefficient.

The heat transfer coefficient is determined according to the equation (2):

$$
k=\frac{M_{1} \cdot c_{p m_{1}} \cdot\left(t_{1}-t_{2}\right)}{H \theta_{m}}
$$

After analyzing the obtained and grouped data, we conclude that at equal mass flow rates, the heat exchange rate is higher for heat exchanger 1 with porous inserts of the highest porosity. The heat exchange rate of the heat exchanger 4 without porous inserts is lower than that for other heat exchangers. The results are presented in Figure 3.

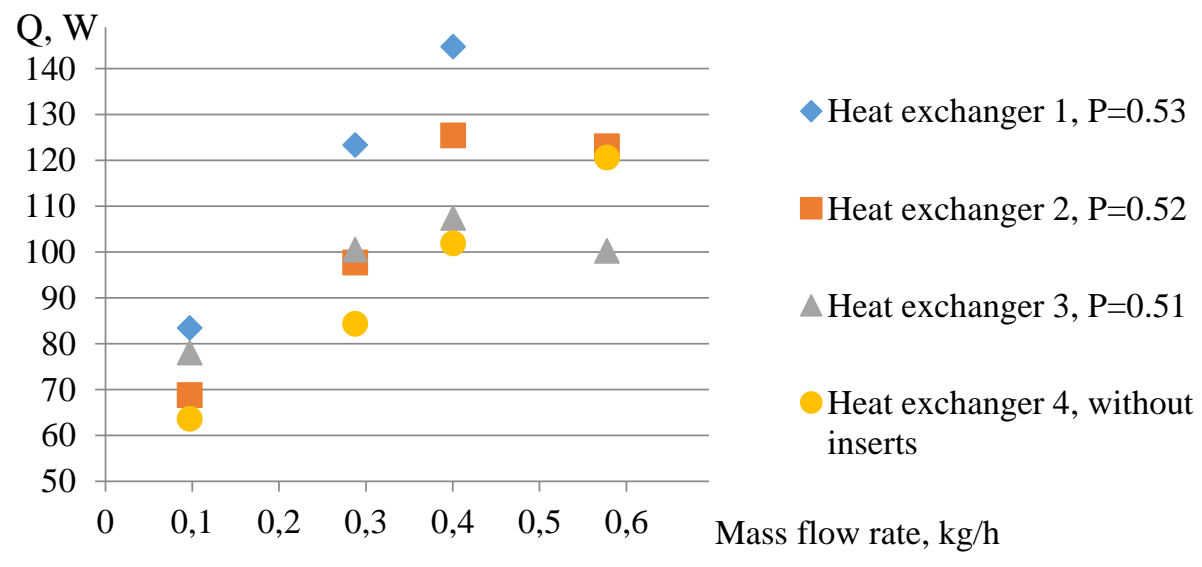

Fig. 3. The results of indirect measurements of the heat transfer intensity in heat exchangers with and without porous inserts. 
A model was developed using the method of introducing slack variables, which makes it possible to estimate the degree of change in heat flux depending on the mass flow rate and type of heat exchanger. As a result, we obtained a relationship between the change in heat flux and the measured values of mass flow in the context of different types of heat exchangers. This relation has the following form (3):

$$
Q=93.58-2.87 \cdot \mathrm{M}_{1}+30.86 \cdot \mathrm{M}_{2}+52.11 \cdot \mathrm{M}_{3}+61.66 \cdot \mathrm{M}_{4}
$$

The determination coefficient of the considered model is statistically significant, and the average approximation error is $8 \%$.

Further we obtained relations between the heat exchange rate and mass flow for each heat exchanger. For this purpose we composed equations for each heat exchanger separately, are shown in Table 1.

Table 1. Equations to compare the heat exchange rate of heat exchangers

\begin{tabular}{|c|c|c|c|}
\hline $\begin{array}{c}\text { Heat exchanger } \\
\text { No. }\end{array}$ & \multicolumn{2}{|c|}{ Intercept term } & $\begin{array}{c}\text { Equations for heat } \\
\text { exchangers }\end{array}$ \\
\hline 1 & $\mathrm{M}_{1}$ & 93.58 & $y=93.58-2.87 \mathrm{M}$ \\
\hline 2 & $\mathrm{M}_{1}+\mathrm{M}_{2}$ & 124.44 & $y=124.44-2.87 \mathrm{M}$ \\
\hline 3 & $\mathrm{M}_{1}+\mathrm{M}_{3}$ & 145.7 & $y=145.7-2.87 \mathrm{M}$ \\
\hline 4 & $\mathrm{M}_{1}+\mathrm{M}_{4}$ & 155.24 & $y=155.24-2.87 \mathrm{M}$ \\
\hline
\end{tabular}

According to these equations we created graphical relations between the intensity of heat exchange and mass flow, presented in Figure 4.



Fig. 4. Empirical data and theoretical lines, which characterize the heat exchange intensity.

The ratio of actual and calculated values of heat exchange intensity shows that heat exchange intensity is higher for heat exchangers Nos. 1,2,3 (with inserts) compared with the heat exchanger 4 (without inserts). In addition, heat transfer intensity increases with increasing of porosity.

\section{Conclusions}

As a consequence, we make the following conclusions:

1. The use of porous metals in the considered designs of heat exchangers allows one to create the higher heat flow compared to conventional ones.

2. It becomes possible to create schemes for refrigeration units with evaporators made of porous metals. 
3. In order to conduct new examinations of promising new materials, we are increasing the cooling capacity of the test unit.

\section{References}

1. A.V. Pustogarov, Investigation of efficient porous cooling, IFJ, 39(3),468-474 (1980)

2. V.A. Mayorov, L.L. Vasiliev, V.M. Polyaev, Porous heat exchange elements classification, design, application, IFJ 47(3), 499-513 (1984)

3. S.V. Belov, Porous metals in mechanical engineering (Mashinostroenie, Moscow, 1981)

4. P.E. Kostikov, V.V. Lozovetsky, Design of fuel elements of high-temperature cooled reactors (Energoatomizdat, Moscow, 1983)

5. F.E. Megerlin, R.W. Murphy, A.E. Bergles, Augmentation of Heat Transfer in Tubes by Use of Mesh and Brush Inserts, Journal of Heat Transfer 96(2), 30-38 (1974)

6. Yu.S. Yuriev, A.P. Kolmakov, A.D. Efanov, Development of a hydrodynamic and thermal model of a porous body and its application to the calculation of nuclear reactors and heat exchangers, Heat transfer in NPP equipment, Leningrad, 9-15 (1986)

7. V.V. Kharitonov, V.N. Fedoseev, Generalization of experimental data on heat transfer in cross-fused bundles of twisted pipes, TVT 28(3), 180-182 (1990)

8. V.A. Maiorov, Current and heat transfer of a single-phase cooler in porous metalceramic materials, Thermal power 1, 64-70 (1978)

9. V.V. Apollonov, P.I. Bystrov, V.F. Goncharov, Prospects for the use of porous structures for cooling elements of power optics, Quantum Electronics 6(12), 2533-2545, (1979)

10. S.R. Ashikhmin, Yu.F. Gortyshov, Mathematical modeling and optimization of thermal and deformation characteristics of porous cooled elements of metal optics (Kazan, 1986)

11. B.M. Galicia, N.N. Inozemtsev, A.V. Pustogarov, Thermal protection of power plants of aircraft (Voenizdat, Moscow, 1983)

12. Yu.V. Polezhaev, F.B. Yurevich, Thermal protection (Energy, Moscow, 1976)

13. I.A. Popov, Hydrodynamics and heat transfer in porous heat exchangers. Heat transfer intensification (Center for Innovative Technologies, Kazan, 2007)

14. Yu.V. Gortyshov, G.B. Muravyev, I.N. Nadyrov, Experimental study of flow and heat transfer in highly porous structures, IFJ 5(3), 357-361 (1987)

15. L.S. Kokarev, V.I. Subbotin, V.I. Fedoseev, On the relationship of hydraulic resistance and heat transfer in porous media, TVT 25(1), 92-97 (1987)

16. B.A. Mayorov, Structure and resistance of a two-phase and evaporating flow in porous materials, Energy and transport 5, 126 (1980)

17. L.L. Vasiliev, V.A. Maiorov, Stability condition for two-phase porous cooling, IFJ 25(2), 237-248 (1973)

18. L.L. Vasiliev, V.A. Maiorov, Hydrodynamic and thermal characteristics of the twophase porous cooling equilibrium system, IFJ 27(5), 260-269 (1974)

19. V.P. Isachenko, V.A. Osipov, A.S. Sukomel, Heat transfer (Energy, Moscow, 1969)

20. A.V. Lykov, Theory of thermal conductivity, (Visshaya Shkola, Moscow, 1967) 